\title{
Produção de brócolis em função das doses de nitrogênio e potássio na fertirrigação das mudas
}

\section{Priscilla Nátaly de Lima Silva ${ }^{1}$, Luis Gustavo de Souza ${ }^{1}$, Mateus Vinicius Narciso Redigolo ${ }^{1}$, Antonio Ismael Inacio Cardoso 1}

${ }^{1}$ Universidade Estadual Paulista, Campus Botucatu, Botucatu, São Paulo, Brasil. E-mail: priscilla_nataly@hotmail.com,
lg.dsouza@ hotmail.com, mateusredigolo@ @otmail.com, ismaeldh@ fca.unesp.br

Recebido: 21/02/2018; Aceito: 26/10/2018.

\section{RESUMO}

Frente à existência de poucos estudos relacionados à aplicação de nitrogênio e potássio na produção de mudas de Brassicáceas, objetivou-se avaliar os efeitos de doses destes nutrientes na fertirrigação de mudas produzidas em substrato à base de fibra da casca de coco sobre a produção de brócolis. Foi utilizado o delineamento experimental em blocos casualizados, em esquema fatorial com quatro doses de $\mathrm{N}\left(0,80,160\right.$ e $\left.240 \mathrm{mg} \mathrm{L}^{-1}\right)$ e quatro doses de $\mathrm{K}$ $\left(0,100,200\right.$ e $\left.300 \mathrm{mg} \mathrm{L}^{-1}\right)$ na fertirrigação das mudas, com quatro repetições. Foram avaliadas a quantidade de macronutrientes e características vegetativas das mudas, como: número de folhas, altura, diâmetro do caule, massa fresca e seca da parte aérea e, na colheita, o número de folhas, diâmetro e massa fresca e seca da inflorescência. Os dados foram submetidos à análise de variância e regressão. As características analisadas nas plantas não foram afetadas pelas doses de potássio. Obteve-se aumento linear para todas as características vegetativas e acúmulo de $\mathrm{N}, \mathrm{K}, \mathrm{Ca}$ e Mg nas mudas, assim como a massa fresca e seca das inflorescências com o aumento das doses de $\mathrm{N}$ testadas.

Palavras-chave: adubação, Brassica oleraceae var. italica, extração de nutrientes, produção de mudas.

\section{Broccoli production depending on nitrogen and potassium rates on seedlings fertigation}

\begin{abstract}
Considering there are few researches about the influence of nitrogen and potassium application in brassica seedling production, this work was carried out to evaluate the effect of these nutrient rates in seedling fertigation grown in coconut fiber substrate on broccoli production. A randomized blocks experimental design, in a factorial scheme with four $\mathrm{N}$ rates $\left(0,80,160\right.$ and $\left.240 \mathrm{mg} \mathrm{L}^{-1}\right)$ and four $\mathrm{K}$ rates $\left(0,100,200\right.$ and $\left.300 \mathrm{mg} \mathrm{L}^{-1}\right)$ in fertigation of seedlings with four replications was used. Macronutrients quantity and vegetative seedlings characteristics, such as the number of leaves, plant height, stem diameter, shoot fresh and dry weight were evaluated, as well as, at harvesting, the number of leaves, diameter, fresh and inflorescence dry weight. Data were submitted to variance and regression analysis. The characteristics analyzed in the plants were not affected by the potassium rates. It was obtained a linear increase for all the vegetative characteristics and accumulation of $\mathrm{N}, \mathrm{K}, \mathrm{Ca}$ and $\mathrm{Mg}$ of the seedlings, as well as the fresh and dry weight of the inflorescences with the increase of the rates of $\mathrm{N}$ tested.
\end{abstract}

Keywords: fertilization, Brassica oleraceae var. italica, nutrients extraction, seedling production. 


\section{Introdução}

O brócolis (Brassica oleracea var. italica) está entre as brássicas de maior importância econômica comercializadas no Brasil. É uma planta bienal, herbácea, cujas partes consumidas são os pedúnculos e botões florais acompanhados de uma parte de caule tenra (Filgueira, 2013).

Normalmente, é propagado por sementes, com produção de mudas em bandejas. Segundo Filgueira (2013), a produção de mudas consiste em uma das etapas mais importantes do sistema produtivo hortícola, necessitando da utilização de insumos de alta qualidade, sendo o substrato um dos insumos de maior importância na sua produção. O substrato deve possuir boa aeração, capacidade de armazenar água, ser livre de contaminações, permitir fácil absorção pelas raízes das plântulas dos nutrientes aplicados, além de ser de baixo custo e facilmente disponível.

A fibra da casca do coco verde é matéria prima importante na produção de substratos para a produção de mudas. A facilidade de produção, baixo custo e alta disponibilidade são algumas vantagens apresentadas por este tipo de substrato. No entanto, o substrato feito a partir das fibras de coco é pobre em nutrientes essenciais para as plantas (Dias et al., 2009; Cardoso; Ustulim Filho, 2013). Portanto, é preciso fornecê-los de acordo com as necessidades da espécie a ser cultivada, adicionando-se adubos em pré-plantio ou em fertirrigação. A fertirrigação consiste na aplicação de fertilizantes solúveis sem que haja excesso ou falta do nutriente, de acordo com a necessidade da planta.

O nitrogênio e o potássio são, geralmente, os macronutrientes extraídos em maiores quantidades pelas hortaliças (Filgueira, 2013). No entanto, este autor recomenda, para a produção de mudas, substrato pobre em nitrogênio, pois doses elevadas deste nutriente podem deixar a muda frágil, com dificuldade de recuperação após o transplante.

Existem muitos trabalhos relacionados à produção de mudas em diversas hortaliças, como abóbora (Higuti et al., 2010), alface (Domingues-Neto et al., 2016; Souza et al., 2008), beterraba (Oliveira et al., 2012), chicória (Cardoso; Ustulim-Filho, 2013), couve-chinesa (Tessaro et al., 2013), melancia (Ramos et al., 2012), pimentão (Santos et al., 2010), quiabo (Costa et al., 2013), repolho (Cimó et al., 2017) e tomate (Rodrigues et al., 2010; Costa et al., 2012). No entanto, a maioria dos substratos estudados é produzida com materiais locais e de difícil reprodução por produtores de outras regiões.

A maioria dos trabalhos relacionados com mudas não é conduzida até o final do ciclo (Magro et al., 2011; Cardoso; Ustulim-Filho, 2013), gerando resultados inconsistentes, uma vez que nem sempre as mudas maiores e/ou com maior massa serão as mais produtivas. Uma muda de qualidade é aquela que não sofre estresse com o transplante e permite desenvolvimento pleno até o final do ciclo. Sendo assim, objetivou-se com este trabalho avaliar o efeito de doses de nitrogênio e potássio fornecidas às mudas via fertirrigação, nas características vegetativas das mudas e na produção de brócolis.

\section{Material e Métodos}

O trabalho foi desenvolvido na Fazenda Experimental São Manuel (22 $46^{\prime} \mathrm{S}, 48^{\circ} 34^{\prime} \mathrm{W}$ e altitude de $740 \mathrm{~m}$ ), localizada no município de São Manuel-SP, no período de 10/10/2012 a 07/02/2013. O clima da região, conforme os critérios adotados por Köppen é Cfa: clima temperado quente (Cunha; Martins, 2009). Os dados climáticos referentes ao período do experimento encontram-se na Figura 1.

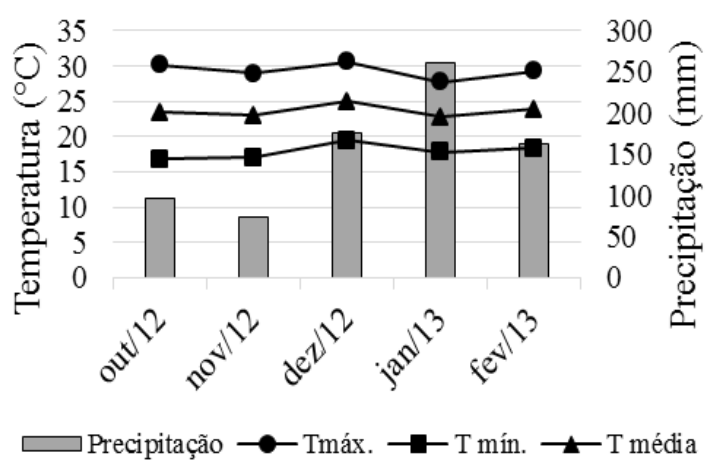

Figura 1. Dados climáticos obtidos junto ao Centro Integrado de Informações Agrometeorológicas (CIIAGRO). São Manuel - SP, 2012/2013.

As mudas foram produzidas em estufa agrícola, tipo arco, com pé direito de $2,8 \mathrm{~m}$, largura de $7 \mathrm{~m}$, comprimento de $20 \mathrm{~m}$ e cobertura de polietileno transparente de $150 \mu \mathrm{m}$ de espessura, com tela antiafídica nas laterais.

Foram 16 tratamentos resultantes do fatorial $4 \times 4$, sendo quatro doses de $\mathrm{N}\left(0,80,160\right.$ e $\left.240 \mathrm{mg} \mathrm{L}^{-1}\right)$ e quatro doses de $\mathrm{K}\left(0,100,200\right.$ e $\left.300 \mathrm{mg} \mathrm{L}^{-1}\right)$ na fertirrigação das mudas, utilizando-se nitrato de amônio ( $34 \%$ de $\mathrm{N}$ ) e cloreto de potássio $\left(60 \%\right.$ de $\mathrm{K}_{2} \mathrm{O}$ ou $33 \%$ de $\mathrm{K}$ ) como fontes de $\mathrm{N}$ e $\mathrm{K}$, respectivamente. $\mathrm{O}$ delineamento foi em blocos ao acaso, com quatro repetições.

Para a definição dos tratamentos, considerou-se a solução de Hoagland e Arnon, citados por Cardoso e Ustulim-Filho (2013), onde os valores de $\mathrm{N}-\mathrm{NO}_{3}$ e de $\mathrm{K}$ são de 210 e $230 \mathrm{mg} \quad \mathrm{L}^{-1}$, respectivamente. Considerando-se que na fase de plântula as necessidades nutricionais são menores que na fase de planta adulta, foram estudadas doses inferiores às desta solução, exceto a maior dose de cada nutriente estudado. Além 
do $\mathrm{N}$ e do $\mathrm{K}$, foram aplicados os demais macronutrientes de acordo com a solução citada: $\mathrm{P}$ (31 $\left.\mathrm{mg} \mathrm{L}{ }^{-1}\right), \mathrm{Ca}\left(160 \mathrm{mg} \mathrm{L}^{-1}\right), \mathrm{Mg}\left(48 \mathrm{mg} \mathrm{L}^{-1}\right)$ e $\mathrm{S}(64 \mathrm{mg} \mathrm{L}$ $\left.{ }^{1}\right)$, utilizando-se superfosfato triplo $\left(41 \% \mathrm{P}_{2} \mathrm{O}_{5}\right.$ e $14 \%$ $\mathrm{Ca})$, cloreto de cálcio ( $24 \% \mathrm{Ca}$ ) e sulfato de magnésio ( $9 \% \mathrm{Mg}$ e $14 \% \mathrm{~S}$ ). As fertirrigações foram realizadas apenas na fase de produção de mudas, antes do transplante das mesmas.

A fertirrigação foi realizada de acordo com os tratamentos aos 7, 14, 21 e 28 dias após a semeadura (DAS), utilizando-se um regador com crivo fino. Foram utilizados $500 \mathrm{~mL}$ da solução por parcela em cada aplicação. Utilizou-se o substrato Golden $\mathrm{Mix}^{\circledR}$, composto por fibras do mesocarpo de cascas de coco, sem adubação inicial ( $\mathrm{C} / \mathrm{N}=63 / 1 ; \mathrm{pH}=4,50 ; \mathrm{N}=0,76 \%$ na matéria seca (MS); $\mathrm{P}_{2} \mathrm{O}_{5}=0,34 \% \mathrm{MS} ; \mathrm{K}_{2} \mathrm{O}=1,22 \% \mathrm{MS}$; $\mathrm{Ca}=0,69 \% \quad \mathrm{MS} ; \quad \mathrm{Mg}=0,25 \% \quad \mathrm{MS} ; \mathrm{S}=0,41 \% \quad \mathrm{MS}$; umidade $=21,30 \%$; M.O. $=86,00 \%$ MS; $C=47,80 \% \mathrm{MS}$ e $\mathrm{Na}=500 \mathrm{mg} \mathrm{kg}^{-1}$ de MS; $\mathrm{Cu}=100 \mathrm{mg} \mathrm{kg}^{-1}$ de MS; $\mathrm{Fe}=2600 \mathrm{mg} \mathrm{kg}^{-1}$ de MS; Mn=266 mg kg-1 de MS; $\mathrm{Zn}=148 \mathrm{mg} \mathrm{kg}^{-1}$ de MS). Quanto à granulometria, cerca de $80 \%$ das partículas encontravam-se na faixa de 0,25 a 2,0 mm.

No dia 10 de outubro de 2012, foi utilizado o híbrido BRO 68 (brócolis tipo cabeça única), com semeadura feita em bandejas de polietileno com 200 células. Em cada bandeja foram utilizadas seis linhas com dez células para cada parcela, totalizando 60 plantas, das quais apenas 32 foram consideradas úteis, pois, das seis linhas, a primeira e a última foram usadas como bordadura, bem como a primeira e a última coluna de cada bandeja.

$\mathrm{Na}$ fase de mudas também foram fornecidos boro e molibdênio em pulverização foliar. $\mathrm{O}$ boro foi fornecido aos 20 e 27 DAS, utilizando-se 1,0 g de ácido bórico por litro de água. $\mathrm{O}$ molibdênio foi fornecido aos $21 \mathrm{e}$ 28 DAS, utilizando-se $1,0 \mathrm{~g}$ de molibdato de sódio por litro de água.

No transplante, aos 30 DAS, 15 mudas por parcela foram utilizadas para avaliar a massa da matéria fresca da parte aérea $\left(\mathrm{g}\right.$ planta $^{-1}$ ), obtida pela pesagem em balança analítica; a altura da parte aérea $(\mathrm{cm})$, desde a superfície do substrato até a ponta da folha mais comprida, com auxílio de régua graduada; o diâmetro do caule $(\mathrm{mm})$ rente ao substrato, com auxílio de um paquímetro digital, e o número de folhas, sem considerar as cotiledonares.

Também foi avaliada a quantidade de nutrientes na parte aérea das mudas. Assim que coletadas, as amostras foram devidamente lavadas. Após a remoção do excesso de água, as amostras foram colocadas em saco de papel, identificadas e levadas para secagem em estufa de circulação forçada de ar a $65{ }^{\circ} \mathrm{C}$, até atingirem massa constante. Posteriormente, com o uso da balança analítica, foi obtida a massa da matéria seca $\left(\mathrm{g}_{\text {planta }}{ }^{-1}\right)$.
Em seguida, cada amostra foi moída em moinho tipo Willey. A digestão sulfúrica foi utilizada para a obtenção do extrato visando à determinação de N. A digestão nítrico-perclórica foi utilizada para a obtenção dos extratos para a determinação dos demais macronutrientes ( $\mathrm{P}, \mathrm{K}, \mathrm{Ca}, \mathrm{Mg}$ e $\mathrm{S}$ ), conforme metodologias apresentadas por Malavolta et al. (1997). A partir das análises químicas foram obtidos os teores de N, P, K, Ca, Mg e S. A quantidade dos nutrientes extraídos foi obtida pela multiplicação do teor de cada nutriente pela massa da matéria seca da amostra.

As mudas foram transplantadas com 30 DAS no espaçamento de 1,0 m entre linhas e 0,5 m entre plantas. $\mathrm{O}$ delineamento experimental foi em blocos casualizados, com as mesmas quatro repetições originais das bandejas, sendo transplantadas seis plantas por parcela, das quais quatro centrais consideradas úteis, excluindo-se a primeira e a última planta da linha em cada parcela.

O solo onde as mudas foram transplantadas é um Latossolo Vermelho Distrófico Típico. Os resultados obtidos na análise química, na camada de 0-20 cm de profundidade, antes da instalação do experimento foram: $\mathrm{pH}_{(\mathrm{CaCl} 2)}=5,9$; matéria orgânica $=16 \mathrm{~g} \mathrm{dm}^{-3}$; $\mathrm{P}_{\text {resina }}=97 \mathrm{mg} \mathrm{dm}^{-3} ; \mathrm{H}+\mathrm{Al}=14 \mathrm{mmol}_{\mathrm{c}} \mathrm{dm}^{-3} ; \mathrm{K}=2,9$ $\mathrm{mmol}_{\mathrm{c}} \mathrm{dm}^{-3} ; \mathrm{Ca}=36 \mathrm{mmol}_{\mathrm{c}} \mathrm{dm}^{-3} ; \mathrm{Mg}=8 \mathrm{mmol}_{\mathrm{c}} \mathrm{dm}^{-3}$; $\mathrm{CTC}=61 \mathrm{mmol}_{\mathrm{c}} \mathrm{dm}^{-3} \mathrm{e} \mathrm{V}=77 \%$. A adubação foi baseada na recomendação de Raij et al. (1997) para o Estado de São Paulo, aplicando-se 60, 200 e $180 \mathrm{~kg} \mathrm{ha}^{-1}$ de $\mathrm{N}, \mathrm{P}_{2} \mathrm{O}_{5}$ e $\mathrm{K}_{2} \mathrm{O}$ na forma de sulfato de amônia ( $21 \%$ $\mathrm{N})$, superfosfato triplo $\left(41 \% \mathrm{P}_{2} \mathrm{O}_{5}\right.$ e $\left.14 \% \mathrm{Ca}\right)$ e cloreto de potássio $\left(60 \% \mathrm{~K}_{2} \mathrm{O}\right)$, respectivamente, além de $60 \mathrm{t}$ $\mathrm{ha}^{-1}$ (base úmida) de composto orgânico da marca comercial Provaso ${ }^{\circledR}$. Foram realizadas adubações em cobertura aos 7, 14, 28 e 35 dias após o transplante, com $0,5 \mathrm{~g}$ de ureia $(45 \% \mathrm{~N})$ por planta em cada adubação. A irrigação foi realizada por aspersão, o controle de plantas daninhas foi efetuado com capinas e o manejo fitossanitário foi realizado sempre que necessário.

A colheita foi realizada de 23 de janeiro até 07 de fevereiro de 2013, à medida que as inflorescências se apresentavam bem formadas e compactas com botões florais ainda unidos (Filgueira, 2013). No dia da colheita de cada inflorescência foram avaliados $o$ número de folhas, diâmetro $(\mathrm{mm})$ e massa (fresca e seca) da inflorescência $\left(\mathrm{g} \mathrm{planta}^{-1}\right)$.

Os resultados foram submetidos à análise de variância e de regressão ( $>0,05)$, utilizando-se o programa Sisvar 5.3 (Ferreira, 2011).

\section{Resultados e Discussão}

Características das mudas antes do transplante

A interação N x K não foi significativa para todas as características avaliadas na fase de mudas aos 30 DAS, 
permitindo discussão de cada nutriente isoladamente. Para todas as características vegetativas das mudas, obteve-se efeito linear para as doses de N (Figura 2). O número de folhas por plântula passou de 2,5 na dose 0 para 3,4 com $240 \mathrm{mg} \mathrm{L}^{-1}$ de $\mathrm{N}$, com aumento de 0,38 folhas para cada acréscimo na concentração da solução nutritiva em $100 \mathrm{mg} \mathrm{L}^{-1}$ de $\mathrm{N}$ (Figura 2A). O mesmo ocorreu para as outras características, ou seja, para cada $100 \mathrm{mg} \mathrm{L}^{-1}$ de $\mathrm{N}$ obteve-se acréscimo de 7,8 $\mathrm{mm}$ para altura da muda (Figura 2B); 0,14 mm para diâmetro do caule (Figura 2C); 0,28 g para massa de matéria fresca (Figura 1D) e 0,04g para massa da matéria seca (Figura 2E). Resultado semelhante foi relatado por Higuti et al. (2010) e por Cardoso e Ustulim Filho (2013) na produção de mudas de abobrinha e chicória, respectivamente, também com substrato à base de fibra de coco com maiores valores de massa da matéria fresca e seca, quando foram aplicadas maiores doses de nitrogênio na fertirrigação das mudas.

Os valores de altura das mudas variaram de 4,8 a $6,7 \mathrm{~cm}$, valores pouco inferiores aos obtidos por Magro et al. (2011), e de 6,0 a 10,0cm em mudas de repolho, que pertencem à mesma espécie ( $B$. oleraceae var. capitata) do brócolis. Já a massa fresca e seca da parte aérea obtida foi semelhante às de Godoy e Cardoso (2005) em couve-flor $(0,6$ a $1,1 \mathrm{~g}$ e 0,10 a $0,25 \mathrm{~g}$ por muda para massa da matéria fresca e seca, respectivamente).

Filgueira (2013) relata que o nitrogênio favorece o desenvolvimento vegetativo das plantas. Este nutriente tem importância fundamental nos processos de absorção iônica, fotossíntese, respiração, multiplicação e diferenciação celular, entre outros, o que explica o aumento no número de folhas, diâmetro de caule e massa da matéria fresca e seca.

As doses de potássio não influenciaram as características avaliadas na fase de mudas: número de folhas (média de 3,0$)$, altura $(5,7 \mathrm{~cm})$, diâmetro do caule $(2,0 \mathrm{~mm})$, massa da matéria fresca $(0,9 \mathrm{~g})$ e seca $(0,15 \mathrm{~g})$ da parte aérea. Estes resultados comprovam o maior efeito do nitrogênio em comparação ao potássio nas características vegetativas das mudas, conforme relatado por Higuti et al. (2010) e Cardoso e Ustulim-Filho (2013) em abobrinha e chicória, respectivamente.

Quanto à quantidade acumulada de macronutrientes nas mudas, apenas fósforo e enxofre não apresentaram diferenças em relação às doses de nitrogênio. Os demais nutrientes apresentaram aumento linear quanto maior a dose de N (Figura 3). A quantidade de um nutriente acumulada pela muda é o produto do teor deste pela massa da matéria seca da mesma. Neste sentido, foi obtido aumento linear para a massa seca (Figura 2E) e para a quantidade acumulada de macronutrientes (Figura 3). Para P e S provavelmente houve um efeito de diluição, ou seja, menores teores destes nutrientes quanto maior a massa da matéria seca. As brássicas são espécies exigentes em S comparativamente a outras espécies (Filgueira, 2013; Cardoso et al., 2016), portanto, talvez sejam necessárias maiores concentrações deste nutriente na solução nutritiva.

Por outro lado, nenhum nutriente apresentou alteração estatística significativa em relação às doses de potássio, com concentrações médias de 151, 21, 348, 96, 32 e $36 \mathrm{mg}$ por plântula de $\mathrm{N}, \mathrm{P}, \mathrm{K}, \mathrm{Ca}, \mathrm{Mg}$ e S, respectivamente. Esta ausência de diferença significativa provavelmente ocorreu porque o $\mathrm{K}$ não influenciou na massa da matéria seca das mudas. Esperava-se que pelo menos a concentração de $\mathrm{K}$ fosse afetada, pois há absorção de "luxo" quando este nutriente está presente em excesso (Ernani et al., 2007). Caso a absorção de luxo se configurasse, deveria ter sido observado maior teor deste nutriente nas mudas, conforme maior dose de $\mathrm{K}$ aplicada. Mesmo na testemunha (dose zero), a muda não apresentou sintomas de deficiência de K. A fibra de coco pode ter fornecido todo o $\mathrm{K}$ necessário para as mudas, pois contém cerca de $1,22 \%$ de $\mathrm{K}_{2} \mathrm{O}$. O potássio não participa de combinações orgânicas, sendo um elemento ativo, porém livre, o que faz com que seja prontamente liberado quando se utilizam materiais orgânicos (Ernani et al., 2007). A ordem de acúmulo dos nutrientes foi $\mathrm{K}>$ $\mathrm{N}>\mathrm{Ca}>\mathrm{S}>\mathrm{Mg}>\mathrm{P}$, mostrando a importância tanto do $\mathrm{K}$ como do $\mathrm{N}$ na composição das mudas, com valores muito superiores aos demais nutrientes. Também, em couve-flor e repolho, pertencentes à mesma espécie do brócolis, o $\mathrm{N}$ e o $\mathrm{K}$ foram os nutrientes mais acumulados na planta (Alves et al., 2011; Corrêa et al., 2013).

\section{Características das plantas na colheita}

A interação N x K também não foi significativa para todas as características avaliadas na colheita, permitindo discussão de cada nutriente isoladamente.

Todas as características analisadas nesta etapa (número e massa da matéria fresca e seca de folhas, diâmetro e massa da matéria fresca e seca da inflorescência) não foram influenciadas pelas doses de potássio na fertirrigação das mudas. A ausência de diferenças na fase de mudas quanto às doses deste nutriente e o fato de todas as plantas terem recebido o mesmo manejo, explicam a ausência de efeito para o potássio. As médias obtidas para o número de folhas, diâmetro, massa fresca e seca das inflorescências foram de 15,3 folhas, $13,6 \mathrm{~cm}, 240,0 \mathrm{~g}$ e $23,5 \mathrm{~g}$, respectivamente. 

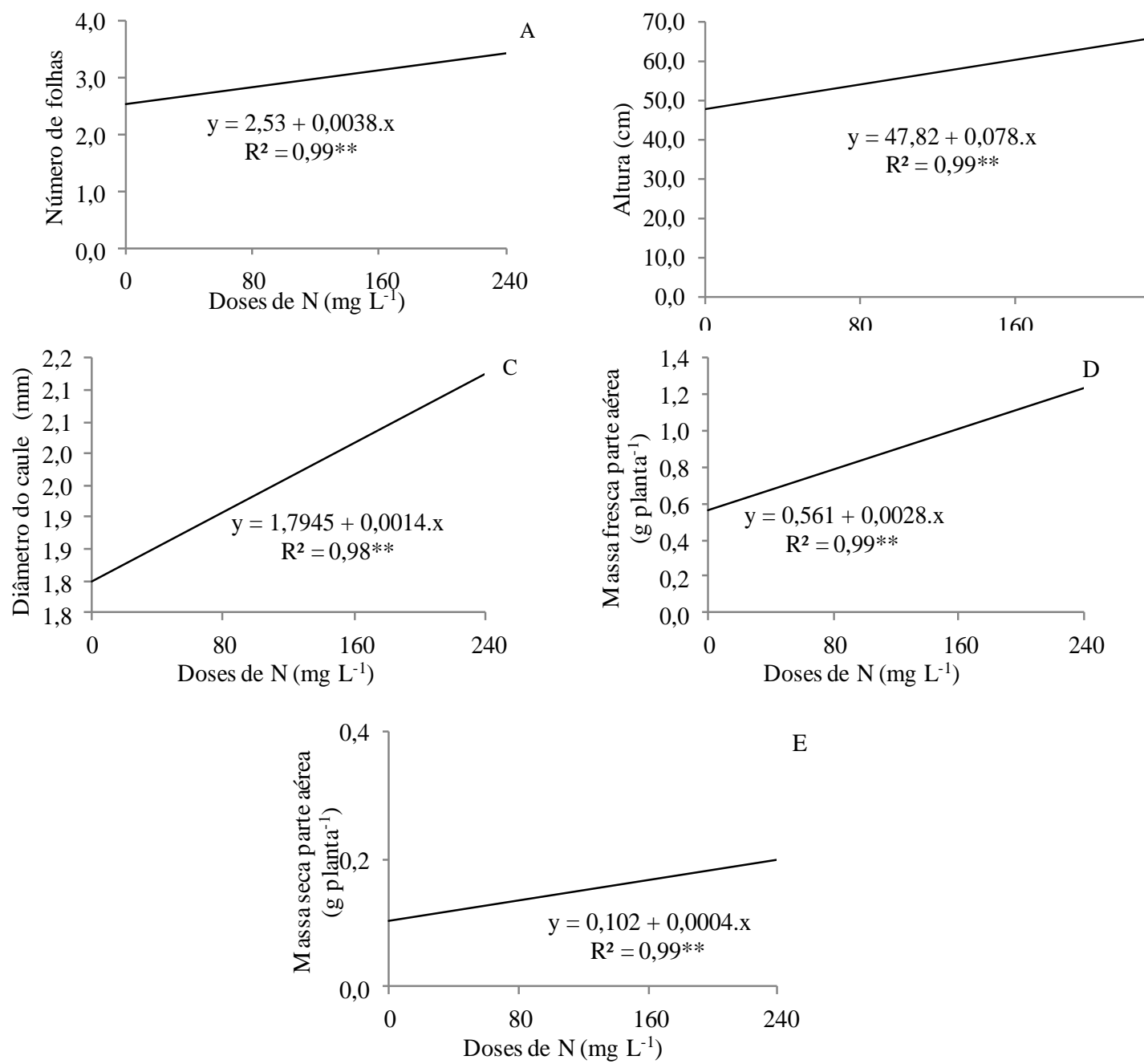

Figura 2. Número de folhas (A), altura (B), diâmetro do caule (C), massa da matéria fresca (D) e seca (E) da parte aérea das mudas de brócolis em função das doses de nitrogênio na fertirrigação das mudas. Botucatu - SP, 2012. ** significativo a $1 \%$ pelo teste F.
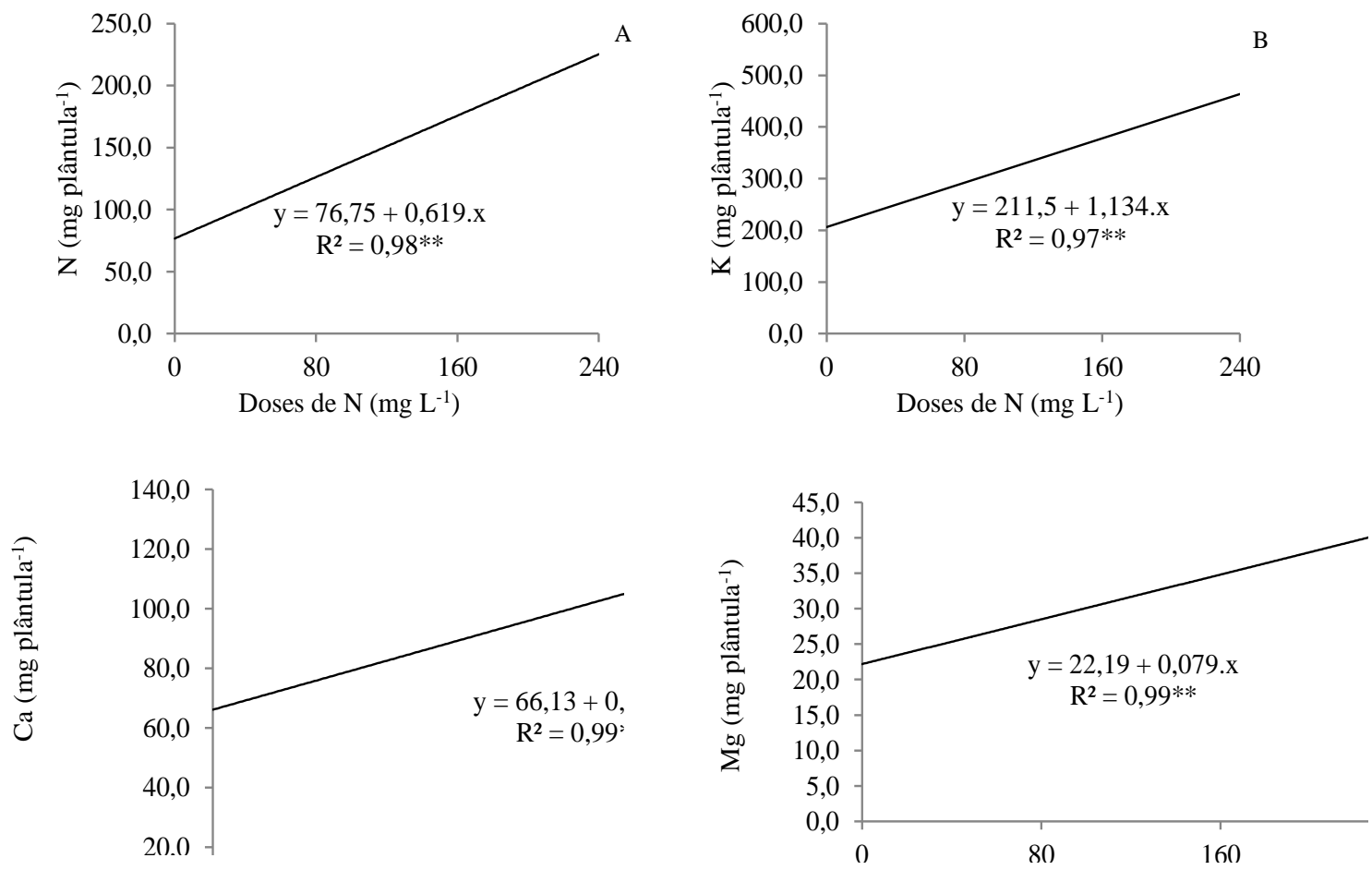

Figura 3. Quantidade acumulada de nitrogênio (A), potássio (B), cálcio (C) e magnésio (D) na parte aérea das mudas de brócolis em função das doses de nitrogênio na fertirrigação das mudas. Botucatu - SP, 2013. ** significativo a 1\% pelo teste $\mathrm{F}$. 
As doses de $\mathrm{N}$ não influenciaram o número de folhas e o diâmetro das inflorescências. O número de folhas (média de 15,3 folhas por planta) esteve abaixo do encontrado por Kano et al. (2008), que foi de 23,5 folhas por planta. O provável motivo foi a grande quantidade de chuvas (Figura 1), causando lixiviação dos nutrientes que foram fornecidos pela adubação e maior incidência de doenças. Quanto ao diâmetro da inflorescência, os valores observados nesse experimento (média de 13,6 cm) foram inferiores aos encontrados por Kano et al. (2008) e por Lalla et al. (2010), que foi de 20,5 e $15,5 \mathrm{~cm}$, respectivamente. No entanto, estes autores realizaram o plantio em épocas favoráveis, enquanto a presente pesquisa foi realizada no verão, época com temperatura mais elevada e precipitação mais intensa, o que favorece a ocorrência de doenças, principalmente podridão negra das crucíferas (Xanthomonas campestris pv. campestris) e desfavorece o pleno desenvolvimento das plantas.

Apesar de ser uma espécie adaptada ao clima ameno (Filgueira, 2013), tem-se produzido brócolis em todas as épocas, e, por falta de maior número de pesquisas nestas épocas desfavoráveis, pouco se conhece sobre o comportamento das plantas nestas épocas. O plantio no verão é feito pelos agricultores pela necessidade em abastecer o mercado consumidor, que requer o produto $\mathrm{o}$ ano inteiro e, normalmente, o desenvolvimento das plantas nesta época é prejudicado. Porém, o valor de venda geralmente é maior e compensa as perdas de produção. A massa da matéria fresca da inflorescência apresentou incremento linear em função das doses de nitrogênio, variando entre 195 e $285 \mathrm{~g}_{\text {planta }}{ }^{-1}$, da menor para a maior dose de nitrogênio, respectivamente, com acréscimo de $33 \mathrm{~g} \mathrm{planta}^{-1}$ para cada aumento em $100 \mathrm{mg} \mathrm{L}^{-1}$ de $\mathrm{N}$ aplicado à muda (Figura 4A e 4B).

Os valores obtidos para a massa da inflorescência foram semelhantes aos observados por Freitas et al. (2011) e inferiores aos 963,2 $\mathrm{g}_{\text {planta }}{ }^{-1}$ relatados por Kano et al. (2008) e por Lalla et al. (2010), que obtiveram $405 \mathrm{~g}$ planta $^{-1}$, todos observados com o híbrido "Legacy" - cultivado em época de temperaturas mais amenas e menor precipitação, ou seja, condições mais favoráveis ao desenvolvimento das plantas de brócolis. Segundo Seabra Júnior et al. (2008), a produção de brócolis no verão é prejudicada pelas condições de alta temperatura e precipitação, levando à formação de inflorescências menores e de pior qualidade visual. Nesta época, a incidência de podridão negra pode ser limitante à produção de brócolis, podendo causar perda total, sendo que, segundo estes autores, os híbridos existentes são muito suscetíveis a este patógeno. Além disto, a elevada precipitação com certeza favoreceu grande lixiviação do $\mathrm{N}$ e do $\mathrm{K}$ aplicados no plantio e em cobertura, potencializada pelo fato de o solo ser arenoso (mais de $80 \%$ de areia).
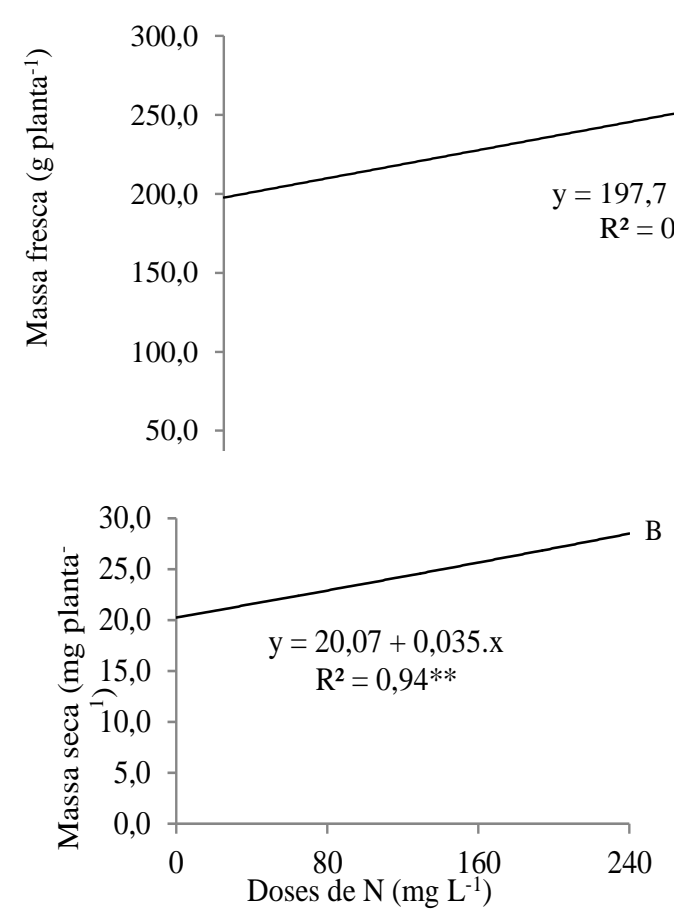

Figura 4. Massa da matéria fresca (A) e seca (B) da inflorescência de brócolis em função das doses de nitrogênio na fertirrigação das mudas. Botucatu - SP, 2013. ** significativo a $1 \%$ pelo teste $\mathrm{F}$.

Da mesma forma, a matéria seca da inflorescência apresentou ajuste linear em função das doses de nitrogênio (Figura 2B). As médias variaram entre $19 \mathrm{e}$ 28 planta $^{-1}$, da menor $\left(0 \mathrm{mg} \mathrm{L}^{-1}\right)$ para a maior dose (240 $\mathrm{mg} \mathrm{L}^{-1}$ ), respectivamente (Figura 4A e 4B).

Segundo Godoy e Cardoso (2005), as épocas mais desfavoráveis são as que normalmente propiciam a diferenciação da qualidade das mudas. Se as condições após o transplante forem ideais, pequenas diferenças na fase de mudas podem não se manter até o final do ciclo, enquanto em condições desfavoráveis as melhores mudas são menos afetadas. Desta maneira, o maior desenvolvimento das mudas promovido pelas maiores doses de nitrogênio favoreceu as plantas em suportar estas condições desfavoráveis. Soma-se a isto o fato de as mudas não terem estiolado, pois, segundo Filgueira (2013), doses elevadas de nitrogênio podem deixar a muda frágil, com dificuldade de recuperação após o transplante. Porém, tal comportamento, estiolamento e fragilidade das mudas não foram observados no presente trabalho, mesmo na maior dose de nitrogênio.

\section{Conclusões}

As doses de potássio em fertirrigação na fase de mudas não influenciaram o desenvolvimento de mudas e produção da inflorescência de brócolis.

$\mathrm{O}$ aumento das doses de nitrogênio na fertirrigação das mudas de brócolis, dentro da faixa de concentração 
avaliada, proporcionou incrementos em todas as características vegetativas das mudas e na massa da matéria fresca e seca da inflorescência.

\section{Agradecimentos \\ À Capes, ao CNPq e à FAPESP pelas bolsas.}

\section{Referências Bibliográficas}

Alves, A.U., Prado, R.M., Correia, M.A.R., Gondim, A.R.O., Cecílio Filho, A.B., Politi, L.S., 2011. Couve-flor cultivada em substrato: marcha de absorção de macronutrientes e micronutrientes. Ciência e Agrotecnologia, 35, 45-55.

Cardoso, A.I.I., Ustulim Filho, A.J., 2013. Produção de chicória em função de doses de nitrogênio e potássio aplicadas na fase de mudas. Horticultura Brasileira, 1, 654-658.

Cardoso, A.I.I., Claudio, M.R.T., Magro, F.O., NakadaFreitas, P.G., 2016. Phosphate fertilization over the accumulation of macronutrients in cauliflower seed production. Horticultura Brasileira, 34,196-201.

Cimó, L., Candian, J.S., Colombari, L.F., Redigolo, M.V.N., Cardoso, A.I.I., 2017. Doses de fósforo na fertirrigação de mudas em substrato a base de fibra de coco e influência na produção de repolho. Irriga, 22, 34-43.

Corrêa, C.V., Cardoso, A.I.I., Claudio, M.T.R., 2013. Produção de repolho em função de doses e fontes de potássio em cobertura. Semina, 34, 2129-2138.

Costa, E., Leal, P.A.M., Benett, C.G.S., Benett, K.S.S., Salamene, L.C.P., 2012. Production of tomato seedlings in different substrates and trays in three protected environments. Engenharia Agrícola, 32, 822-830.

Costa, E., Souza, T.G., Benteo, G.L., Benett, K.S.S., Benett, C.G.S., 2013. Okra seedlings production in protected environment, testing substrates and producing fruits in field. Horticultura Brasileira, 31, 8-14.

Cunha, A.R., Martins, D., 2009. Classificação climática para os municípios de Botucatu e São Manuel, SP. Irriga, 14, 1-11.

Dias, T.J., Pereira, W.E., Cavalcante, L.F., Raposo, R.W.C., Freire, J.L.O., 2009. Desenvolvimento e qualidade nutricional de mudas de mangabeiras cultivadas em substratos contendo fibra de coco e adubação fosfatada. Revista Brasileira de Fruticultura, 31, 512-523.

Domingues Neto, F.J., Pimentel Júnior, A., Yoshimi, F.K., Garcia, R.D., Gualberto, R., 2016. Substratos na formação de mudas, no desenvolvimento e produção da alface crespa. Revista Mirante, 9, 311-320.

Ernani, P.R., Almeida, J.A., Santos, F.C., 2007. Potássio, in: Novais, R.F., Alvarez, V.H., Barros, N.F., Fontes, R.L.F., Cantarutti, R.B., Neves, J.C.L. Fertilidade do solo. SBCS/UFV, pp. 551-594.

Ferreira, D.F., 2011. Sisvar: a computer statistical analysis system. Ciência e Agrotecnologia, 35, 1039-1042.

Filgueira, F.A.R., 2013. Novo manual de olericultura: agrotecnologia moderna na produção e comercialização de hortaliças, terceira ed. UFV, Viçosa-MG.
Freitas, G.B., Rocha, M.S., Santos, R.H.S., Freitas, L.M.S., Resende, L.A., 2011. Broccoli yield in response to topdressing fertilization with green manure and biofertilizer. Revista Ceres, 58, 645-650.

Godoy, M.C., Cardoso, A.I.I., 2005. Produtividade da couveflor em função da idade de transplantio das mudas produzidas e tamanhos de células na bandeja. Horticultura Brasileira, 23, 837-840.

Higuti, A.R.O., Salata, A.C., Godoy, A.R., Cardoso, A.I.I., 2010. Produção de mudas de abóbora com diferentes doses de nitrogênio e potássio. Bragantia, 69, 377-380.

Kano, C., Godoy, A.R., Higuti, A.R.O., Castro, M.M., Cardoso, A.I.I., 2008. Produção de couve-brócolo em função do tipo de bandeja e idade das mudas. Ciência e Agrotecnologia, 32, 110-114.

Lalla, J.G., Laura, V.A., Rodrigues, A.P.D.C., Seabra Júnior, S., Silveira, D.S., Zago, V.H., Dornas, M.F., 2010. Competição de cultivares de brócolos tipo cabeça única em Campo Grande. Horticultura Brasileira, 28, 360-363.

Magro, F.O., Salata, A.C., Bertolini, E.V., Cardoso, A.I.I., 2011. Produção de repolho em função da idade das mudas. Agro@mbiente On-line, 5, 119-123.

Malavolta, E., Vitti, G. C., Oliveira, S.A., 1997. Avaliação do estado nutricional das plantas, princípios e aplicações, segunda ed. Potafós, Piracicaba.

Oliveira, L.C., Costa, E., Cortelassi, J.A.S., Rodrigues, E.T., 2012. Formation of beetroot seedlings in different protected environments, substrates and containers in Aquidauana region, State of Mato Grosso do Sul, Brazil. Engenharia Agrícola, 32, 415-422.

Raij, B.V., Cantarella, H., Quaggio, J.A., Furlani, A.M.C., 1997. Recomendações de adubação e calagem para o estado de São Paulo, segunda ed. Instituto Agronômico e Fundação IAC, Campinas.

Ramos, A.R.P., Dias, R.C.S., Aragão, C.A., Mendes, M.A.S., 2012. Mudas de melancia produzidas com substrato à base de pó de coco e soluções nutritivas. Horticultura Brasileira, 30, 339-344.

Rodrigues, E.T., Leal, P.A.M., Costa, E., Paula, T.S., Gomes, V.A., 2010. Produção de mudas de tomateiro em diferentes substratos e recipientes em ambiente protegido. Horticultura Brasileira, 28, 483-488

Santos, M. R., Sediyama, M.A.N., Salgado, L.T., Vidigal, S.M., Reigado, F. R., 2010. Produção de mudas de pimentão em substratos à base de vermicomposto. Bioscience Journal, $26,572-578$

Seabra Júnior, S., Paixão, G.S., Maringoni, C., Goto, R., Camara, R.C., 2008. Reação de híbridos de brócolis 'tipo cabeça única' à podridão negra. Summa Phytopathologica, 34, 76-77.

Souza, S.R., Fontinele, Y.R., Saldanha, C.S., Araújo Neto, S.E., Kusdra, J.F., 2008. Produção de mudas de alface com o uso de substrato preparado com coprólitos de minhoca. Ciência e Agrotecnologia, 32, 115-121.

Tessaro, D., Matter, J.M., Kuczman, O., Furtado, L., Costa, L.A.M., Costa, M.S.S.M., 2013. Produção agroecológica de mudas e desenvolvimento a campo de couve-chinesa. Ciência Rural, 43, 831-837. 